\title{
Individual caspase-10 isoforms play distinct and opposing roles in the initiation of death receptor-mediated tumour cell apoptosis
}

\author{
A Mühlethaler-Mottet ${ }^{\star, 1}$, M Flahaut ${ }^{1}, \mathrm{~K}$ Balmas Bourloud ${ }^{1}, \mathrm{~K} \mathrm{Nardou}^{1}{ }^{1}$, A Coulon $^{1}$, J Liberman ${ }^{1}, \mathrm{M} \mathrm{Thome}^{2}$ and N Gross ${ }^{1}$
}

The cysteine protease caspase-8 is an essential executioner of the death receptor (DR) apoptotic pathway. The physiological function of its homologue caspase-10 remains poorly understood, and the ability of caspase-10 to substitute for caspase-8 in the DR apoptotic pathway is still controversial. Here, we analysed the particular contribution of caspase-10 isoforms to DR-mediated apoptosis in neuroblastoma (NB) cells characterised by their resistance to DR signalling. Silencing of caspase-8 in tumour necrosis factor-related apoptosis-inducing ligand (TRAIL)-sensitive NB cells resulted in complete resistance to TRAIL, which could be reverted by overexpression of caspase-10A or -10D. Overexpression experiments in various caspase-8-expressing tumour cells also demonstrated that caspase-10A and $-10 \mathrm{D}$ isoforms strongly increased TRAIL and FasL sensitivity, whereas caspase-10B or -10G had no effect or were weakly anti-apoptotic. Further investigations revealed that the unique $C$-terminal end of caspase-10B was responsible for its degradation by the ubiquitin-proteasome pathway and for its lack of pro-apoptotic activity compared with caspase-10A and -10D. These data highlight in several tumour cell types, a differential pro- or antiapoptotic role for the distinct caspase-10 isoforms in DR signalling, which may be relevant for fine tuning of apoptosis initiation. Cell Death and Disease (2011) 2, e125; doi:10.1038/cddis.2011.8; published online 3 March 2011

Subject Category: Cancer

Acquired resistance to apoptosis has a pivotal role in tumourigenesis, malignancy, metastatic potential and drug resistance, and therefore is considered as a hallmark of cancers. ${ }^{1}$ Caspases are the main executioners of the two distinct apoptotic pathways. The death receptor (DR) pathway is triggered by the binding of death ligands (tumour necrosis factor-related apoptosis-inducing ligand (TRAIL), FasL or $\mathrm{TNF}-\alpha$ ) resulting in receptor aggregation and recruitment of the initiator procaspase-8 and -10 to the death-inducing signalling complex (DISC). ${ }^{2}$ Procaspase- 8 or -10 dimerisation is necessary for their activation by autocatalytic processing, leading to the activation of the effector caspases (caspase-3, -6 and -7 ) and the pro-apoptotic protein Bid that triggers the mitochondrial pathway. ${ }^{3-5}$ Caspase- 8 is also implicated in the amplification of the mitochondrial apoptotic pathway via caspase-3-mediated activation of caspases-8 and -9 . $^{6}$ Recently, caspase-10 was shown to be similarly involved in the intrinsic pathway induced by cytotoxic drugs, downstream of mitochondria activation through a FADD-dependent but death receptor-independent mechanism. ${ }^{7-9}$ Caspase- 8 and -10 are thus both involved in feedback amplification loops of the intrinsic apoptotic pathway.

Caspase-10 is highly homologous to caspase- 8 and the CASP10 gene is linked to the CASP8 gene at the human chromosome locus 2q33-34, suggesting tandem duplication. ${ }^{10,11}$ However, in contrast to caspase-8, no ortholog of human caspase-10 exists in mice. Different splice variants of caspase- 8 and -10 mRNA have been identified, which lead to the production of several closely related isoforms., ${ }^{3,1-14}$ Although the two full-length caspase- $8 A$ and $B$ isoforms are pro-apoptotic, the truncated caspase-8L isoform, acting as dominant-negative isoform, is anti-apoptotic (Figure 1a). ${ }^{3}$ Caspase-10 is expressed as three full-length isoforms, caspase-10A, B and D, and a truncated isoform, caspase$10 \mathrm{G}$, consisting of only the two death effector domains (DEDs) ${ }^{12-14}$ (Figure 1a). This smaller isoform was initially described as caspase-10C, but its transcript is supposed to be untranslated because of nonsense-mediated mRNA decay. ${ }^{13}$

A redundant function for caspase- 8 and -10 has long been assumed because of their high sequence homology. Contrary to caspase-8, the physiological function of caspase-10 and its specific contribution to the apoptotic cascade remain poorly understood. Both caspase- 8 and -10 are recruited to and auto-catalytically activated at the DISC with similar kinetics, and may function independently of each other. ${ }^{4,15,16}$ Nevertheless, the ability of caspase-10 to substitute for caspase-8 in DR apoptosis is still controversial. ${ }^{4,15,16}$ A tumour-suppressor function for caspase-10 has been proposed as acquired inactivating mutations of caspase-10 were identified in tumour cells from patients with non-Hodgkin's lymphomas ${ }^{17}$ and solid tumours. ${ }^{18-20}$ Post-transcriptional downregulation of caspase-10 was described in some tumours cell lines ${ }^{15}$ and both

${ }^{1}$ Department of Paediatrics, Paediatric Oncology Research, University Hospital CHUV, CH-1011 Lausanne, Switzerland and ${ }^{2}$ Department of Biochemistry, University of Lausanne, $\mathrm{CH}-1066$ Epalinges, Switzerland

${ }^{*}$ Corresponding author: A Mühlethaler-Mottet, Department of Paediatrics, Paediatric Oncology Research, University Hospital CHUV, Rue du Bugnon 46, CH-1011 Lausanne, Switzerland Tel: + 41213143 615; Fax: + 41213143 664; E-mail: Annick.Muhlethaler @chuv.ch

Keywords: caspase-10; caspase-8; apoptosis; TRAIL; neuroblastoma

Abbreviations: NB, neuroblastoma; TRAIL, tumour necrosis factor-related apoptosis-inducing ligand; DISC, death-inducing signalling complex; DR, death receptor; $\mathrm{DED}$, death effector domain; CHX, cycloheximide; PBL, peripheral blood lymphocyte

Received 18.11.10; revised 17.1.11; accepted 20.1.11; Edited by A Stephanou 
a

\begin{tabular}{|c|c|c|c|c|}
\hline \multirow[b]{3}{*}{ Caspase-10A } & Prodomain & \multicolumn{2}{|c|}{ Proteolytic domain } & \multirow{3}{*}{$\begin{array}{c}\text { MW } \\
54.6\end{array}$} \\
\hline & p25 & p17 & p12 & \\
\hline & DED DED & & & \\
\hline asp & DED DED & & & \\
\hline$s p$ & DED DED & & & \\
\hline aspase-10G & DED DED & p22 & $\mathrm{p} 12$ & \\
\hline
\end{tabular}

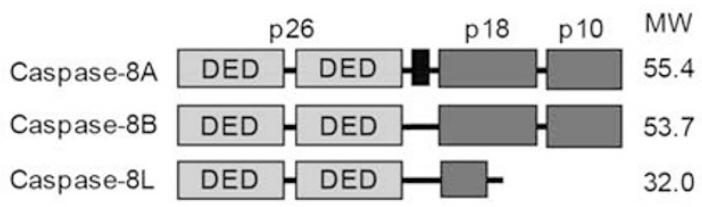
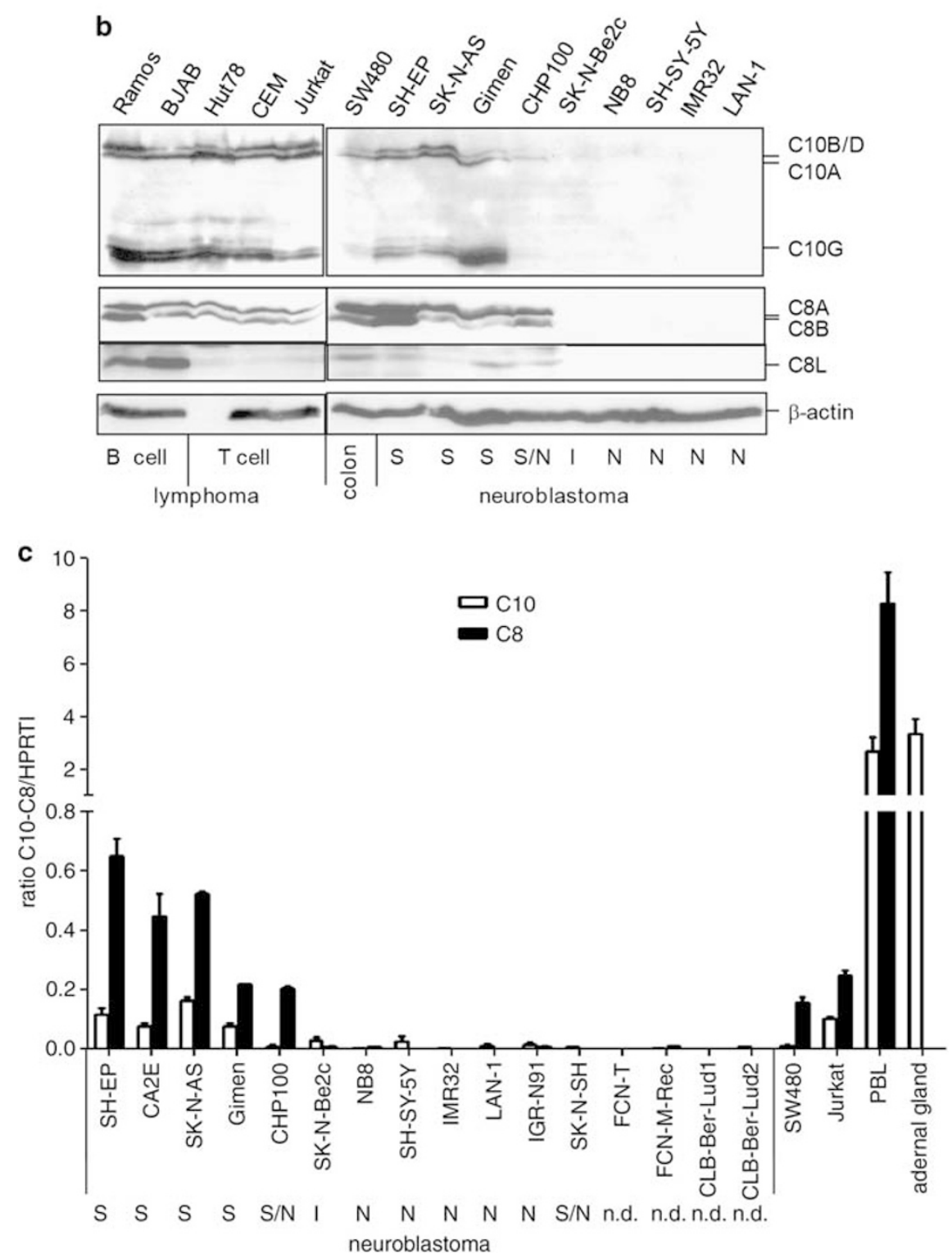

Figure 1 Analysis of the expression levels of caspase-8 and -10 isoforms. (a) Schematic representation of caspase-10 and -8 protein isoforms. Regions encoded by alternative exons are indicated. DED, death effector domain. (b) Whole cell extracts from various cell lines were loaded on a $15 \%$ SDS-polyacrylamide gel as described, ${ }^{40}$ and analysed by immunoblotting for the expression of caspase-8 and -10 isoforms. The three types of NB cells (S, substrate adherent; I, intermediate; N, neuroblastic) are represented. n.d., not determined. The immunoblot for endogenous caspase-10 detection were revealed using the ECL Advanced western blotting substrate for stronger signal detection. (c) Caspase-8 and -10 mRNA expression levels in tumour cells were compared by semi-quantitative real-time PCR. Plots represent means of three separate experiments 
caspases-8 and -10 are frequently co-silenced in childhood tumours. ${ }^{19}$ Finally, caspase-10 is more resistant than caspase- 8 to caspase inhibitors (CrmA and z-VAD-fmk) and both caspases have different substrate specificities suggesting distinct roles of the two caspases. $4,21,22$

Neuroblastoma (NB) is one of the deadliest solid tumours in childhood. ${ }^{23}$ This tumour exhibits a clinically and biologically heterogeneous behaviour, in part attributed to apoptosis deregulation. ${ }^{23}$ The DR pathway is indeed frequently affected in aggressive NB, where inactivation of CASP8 gene expression, mostly by gene silencing, and post-transcriptional inactivation of CASP10 gene have been described. ${ }^{19,24,25} \mathrm{NB}$ cell lines present as $\mathrm{S}$ - or $\mathrm{N}$-types according to their phenotypic characteristics. N-type cells generally display MYCN amplification and recapitulate the aggressive behaviour of stage 4 tumours with tumourigenic properties. Although S-type cells harbour a single MYCN copy and are less tumourigenic. ${ }^{26}$ S-type cells express caspase- 8 and are sensitive to TRAIL, while caspase- 8 is silenced in $\mathrm{N}$-type cells that are resistant to TRAIL. ${ }^{25}$

We have previously shown that restoration of caspase-8 expression in caspase-8/-10-deficient NB cell line was necessary and sufficient to fully restore TRAIL sensitivity. ${ }^{27}$ In this report, we have investigated the yet unexplored contribution of caspase-10 to the resistance of NB and other tumour cells to TRAIL- and Fas-induced apoptosis, its ability to substitute for caspase-8, and the particular role of the four distinct caspase-10 isoforms in extrinsic apoptosis. We demonstrate for the first time the ability of caspase-10 to substitute for caspase-8 in apoptosis initiation in NB cells. Thus, the reduced caspase-10 expression, which was not restricted to NB, may be involved in tumour resistance to TRAIL. Moreover, our data reveal that individual caspase-10 isoforms have distinct and even opposing roles in mediating extrinsic apoptotic signals. Collectively, our findings highlight a possible role for relative caspase-10 isoform expression levels in the regulation of the extrinsic apoptotic response.

\section{Results}

Caspase-10 silencing in NB is cell-type related. To assess individual roles for caspase-8 and -10 isoforms (Figure 1a), their expression levels were analysed by immunoblotting in NB and other tumour cell lines (Figure 1b). Caspase-8 and -10 were generally silenced in N-type NB cells, while in S-type cells both caspases were always co-expressed, although at variable ratios between cell lines (Figure $1 b$ ). NB cells mainly expressed the full-length caspase-10 isoforms, while the truncated caspase-10G isoform was only predominant in Gimen cells. The distinct caspase- 8 and -10 isoforms were also detected in $B$ and $T$ lymphoma cell lines (Figure $1 b$ ).

Analyses of caspase- 8 and -10 mRNA expression levels revealed that caspase-10 mRNA was low when compared with caspase-8 mRNA in NB, SW480 and Jurkat cells, while it was highly expressed in normal peripheral blood lymphocyte (PBL) and adrenal gland (Figure 1c). Interestingly, caspase-10 mRNA as well as protein expression was either not or faintly detectable in N-type NB cells, suggesting that in NB cells caspase-10 silencing occurred mostly at the transcriptional level (Figure 1c).
Endogenous caspase-10 expression is not sufficient to render NB cells TRAIL-sensitive. Next, the respective roles of caspase-8 and -10 in initiating DR apoptosis in NB cells was analysed by manipulating the relative expression levels of caspase- 8 and -10 isoforms. First, downregulation of both caspase-8A and -B using shRNA resulted in a strongly reduced caspase-8 expression in S-type SH-EP-shC8 and SK-N-AS-shC8 NB cells compared with control cells (Figure 2a), while caspase-10 expression level remained unchanged (data not shown). Owing to caspase-8 silencing, SH-EP-shC8 and SK-N-AS-shC8 cells became fully resistant to TRAIL (Figure $2 \mathrm{~b}$ ), resulting in apoptosis resistance, as demonstrated in SH-EP-shC8 cells (Figure 2c). In SH-EPshC8 cells treated with TRAIL, no cleavage of caspase-8, caspase-10, caspase-3 or Bid could be measured, while their proteolytic cleavage was easily detectable in SH-EP-RNAC control cells (Figure 2d). These observations were confirmed by caspase activity assays showing that caspase-3-like activity was abolished in SH-EP-shC8 and SK-N-AS-shC8 (Figure 2e). These results suggest that in caspase-8-silenced S-type NB cells, the low endogenous caspase-10 expression level is not sufficient to initiate apoptosis, even in the presence of a weak amount of caspase-8 protein.

To explore the specific participation of caspase-10 in the extrinsic death cascade, caspase-10 isoforms were then transiently downregulated using siRNAs targeting all caspase-10 isoforms, or siRNAs specific for individual caspase10 isoforms. Downregulation of individual or all caspase-10 isoforms in SH-EP cells did not affect TRAIL sensitivity, while caspase-8 downregulation resulted in full resistance (Figure 2f). Similar results were obtained in SW480 cells (data not shown). Thus, endogenous levels of caspase-10 are not sufficient to confer TRAIL-sensitivity to NB cells.

Caspase-10A or -10D isoforms can substitute for caspase-8 in the initiation extrinsic apoptosis. We have previously demonstrated that stable restoration of caspase-8A expression in the TRAIL resistant, caspase-8/-10-negative IGR$\mathrm{N}-91 \mathrm{NB}$ cell line was sufficient to fully sensitise these cells to TRAIL. ${ }^{27}$ Thus, to analyse the ability of individual caspase-10 isoforms to substitute for caspase- 8 in the initiation of DR apoptosis, the full-length caspase- 10 isoforms $A, B$ and $D$ were stably overexpressed in the IGR-N-91 cell line. Interestingly, while caspase-10B overexpression failed to sensitise the IGR$\mathrm{N}-91-\mathrm{C} 10 \mathrm{~B}$ cells to TRAIL (Figure 3a), caspase-10A or $-10 \mathrm{D}$ overexpression in IGR-N-91 induced a clear TRAIL-mediated apoptotic signal (Figure $3 b$ ). Similar results were obtained in the caspase-8-silenced SH-EP-shC8 cells (Figure 3c). Caspase$10 \mathrm{~A}$ or $-10 \mathrm{D}$ overexpression did not affect the proliferation capacity of IGR-N-91 cells (data not shown). These results indicate that exogenous expression of caspase-10A or $-10 \mathrm{D}$, but not caspase-10B, are able to promote TRAIL-mediated apoptosis in NB cells, and thus can substitute for caspase-8 in the initiation of the apoptotic cascade.

Distinct caspase-10 isoforms induce opposed apoptotic signals in NB cells. The above-described results suggest that caspase-10 isoforms might exhibit distinct abilities to initiate apoptosis in NB cells. To further verify their respective role, the four distinct $\mathrm{C} 10$ isoforms were overexpressed in the 

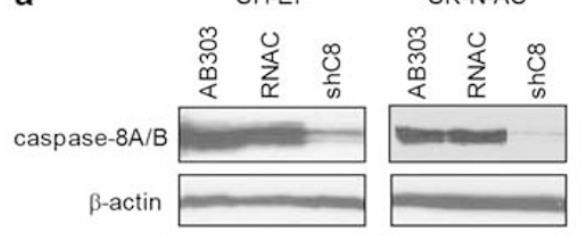

b

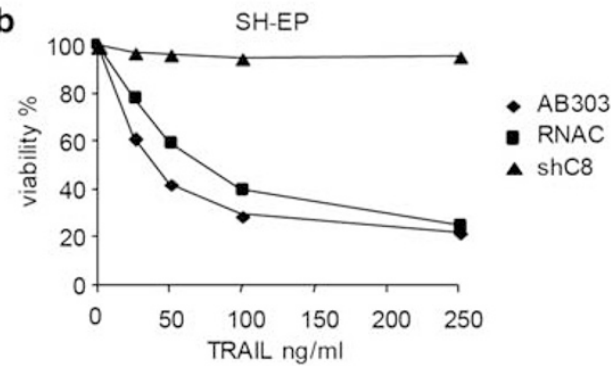

C

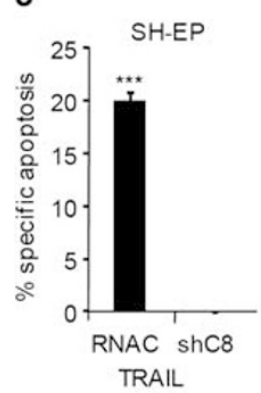

d

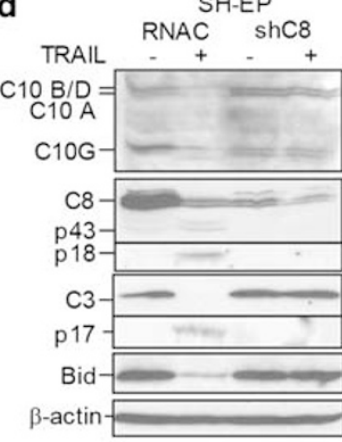

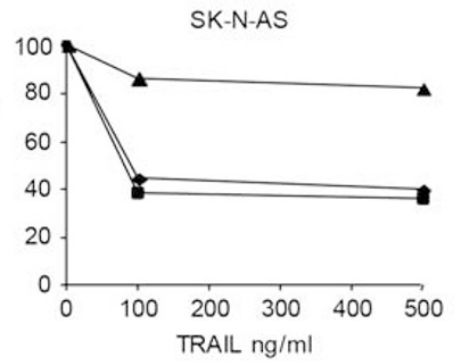

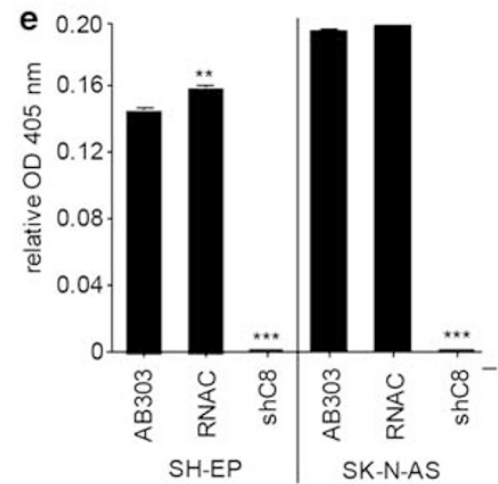
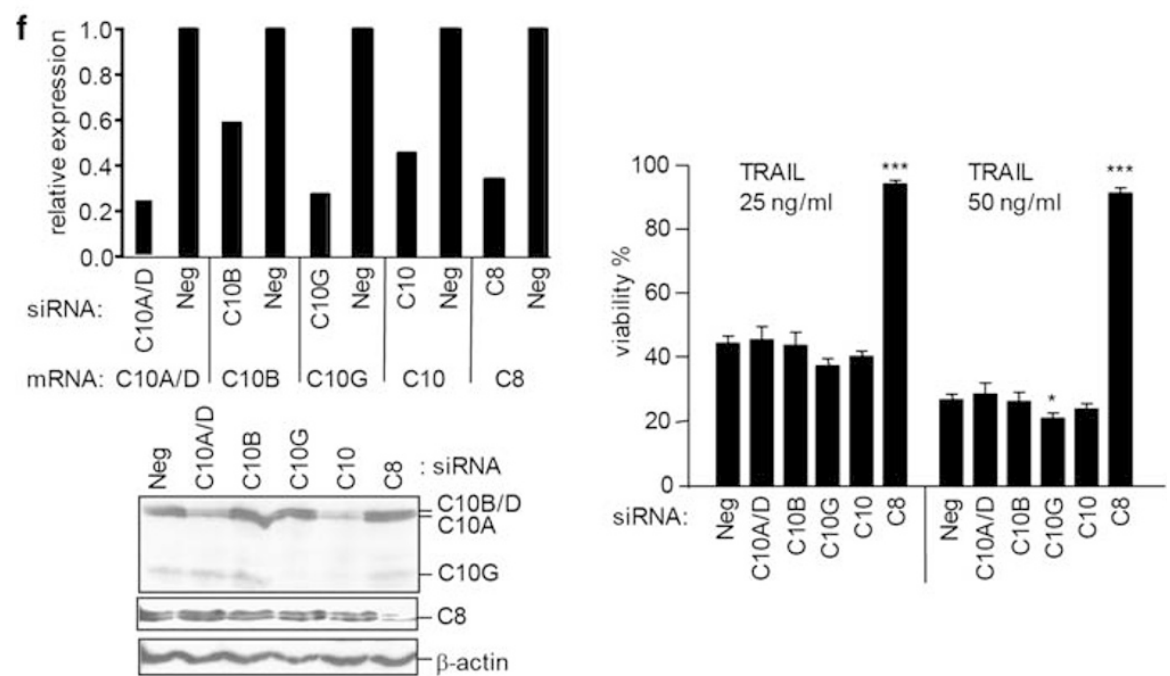

Figure 2 Endogenous caspase-10 levels are not sufficient to initiate TRAIL-mediated apoptosis in NB cells. (a) SH-EP or SK-N-AS cells infected with the empty vector (AB303), a nonspecific shRNA (RNAC), or caspase-8 shRNA (shC8) were analysed by immunoblotting for the presence of caspase-8. $\beta$-Actin was used as loading control. (b) Cell viability was measured in SH-EP- and SK-N-AS-AB303 (diamond), -RNAC (square) and -shC8 (triangle) cells treated with increasing amount of TRAIL for $48 \mathrm{~h}$. A representative experiment out of three is shown. (c) Percentage of sub-G1 apoptotic cells detected by the PI staining method after stimulation with TRAIL (100 ng/ml) are indicated, mean of three experiments are shown ( $\left.{ }^{* \star *} \mathrm{P}<0.0001\right)$. (d) SH-EP cells were untreated or treated with $100 \mathrm{ng}$ of TRAlL for $16 \mathrm{~h}$. Immunoblotting analysis of caspase-8, -10 , -3 and Bid processing. $\beta$-Actin was used as loading control, as in further immunoblotting analyses. (e) Hydrolysis of DEVD-pNA was measured in cell lysates from SH-EP and SK-N-AS-infected cells treated with 50 or $250 \mathrm{ng} / \mathrm{ml}$ of TRAIL for $16 \mathrm{~h}$, respectively. Relative OD values at $405 \mathrm{~nm}$ of stimulated compared with unstimulated cells of one experiment performed in duplicates are represented. $\left.{ }^{\star \star \star} P<0.0001,{ }^{\star \star} P<0.01\right)$. (f) SH-EP cells were transiently transfected with the indicated siRNAs (siNeg, negative control siRNA). Relative expression levels of the indicated mRNA compared with HPRT1 mRNA as measured by real-time PCR are plotted in the graph (upper left panel). Immunoblotting analysis of caspase-10 and -8 expression in SH-EP transfected for $48 \mathrm{~h}$ with the indicated siRNAs (bottom left panel). Cell viability of cells treated for $48 \mathrm{~h}$ with indicated doses of TRAIL (right panel) is represented $\left({ }^{\star \star *} P<0.0001\right)$ 
a

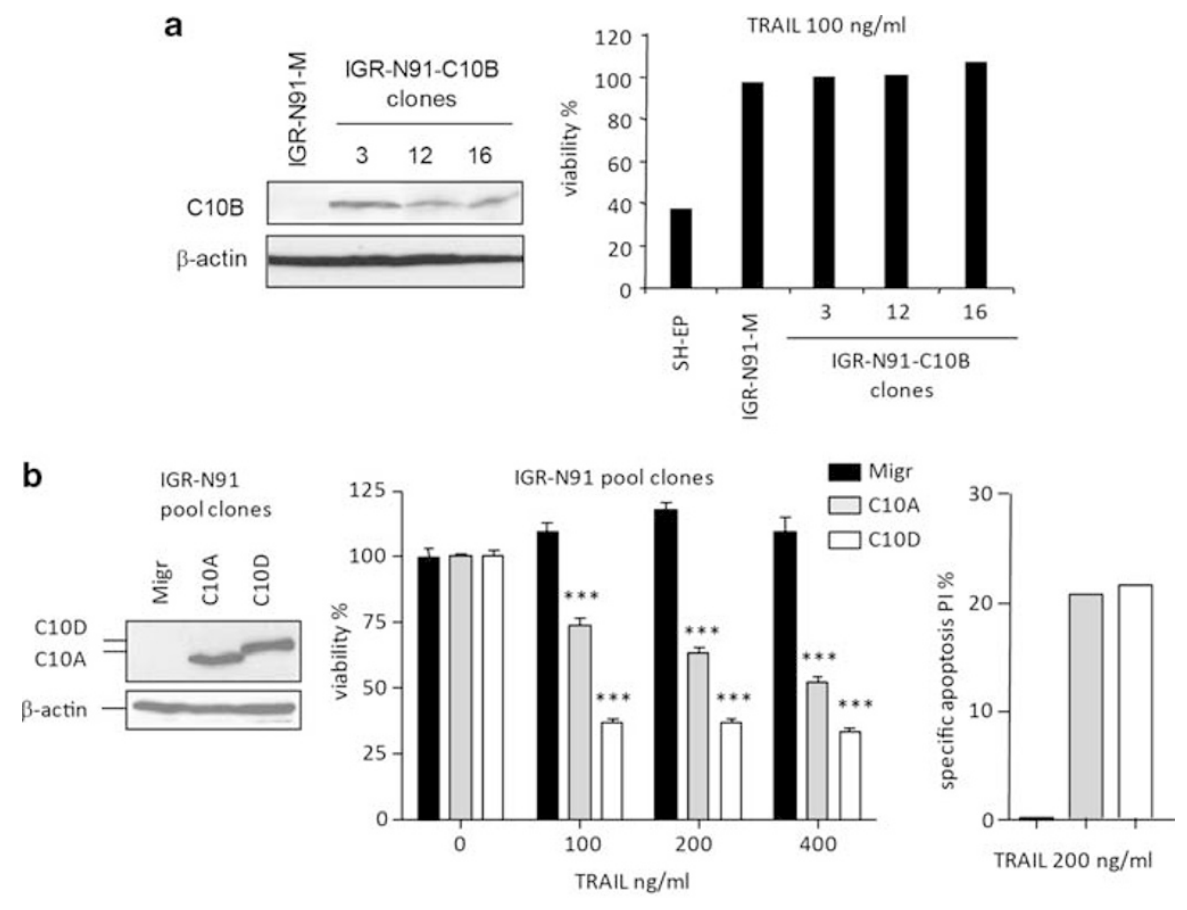

C

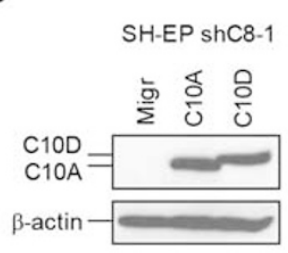

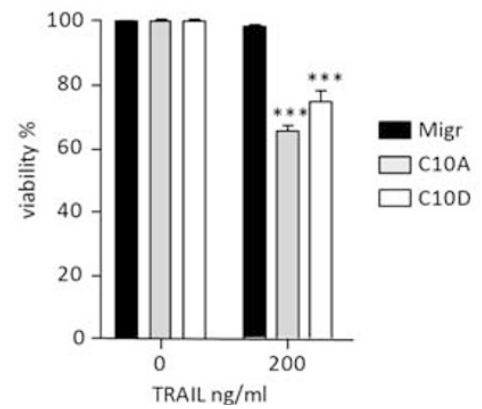

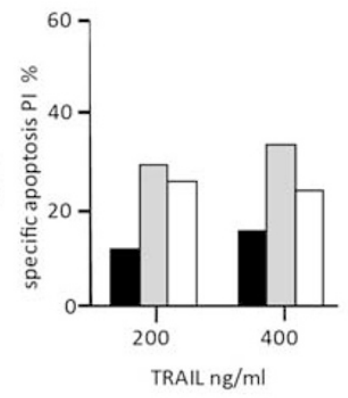

Figure 3 Caspase-10A or -10D isoforms can substitute for caspase-8 in the initiation of the apoptotic cascade. (a) Immunoblotting analysis of caspase-10 expression in IGR-N-91 clones transduced with the empty vector (M) or with vector encoding for caspase-10B, or SH-EP cells (positive control). Cell viability was measured in cells treated with TRAIL (100 ng/ml) for $48 \mathrm{~h}$. (b) Immunoblotting analysis of caspase-8, caspase-10, and $\beta$-actin expression in IGR-N-91 cells transduced with the empty vector (Migr) or with vector encoding for caspase-10A or -10D (pool of five clones each). Cell viability was measured in the pool of clones of IGR-N-91-Migr, -C10A and -C10D cells treated with the indicated doses of TRAIL for $48 \mathrm{~h}$. Mean of two experiments performed in quadruplicates are shown $\left.{ }^{* * \star} P<0.0001\right)$. Percentage of sub-G1 apoptotic cells after stimulation with TRAIL are indicated, one representative experiment is shown. (c) SH-EP-shC8 cells transduced with the empty vector (Migr) or with vector encoding for caspase-10A or $-10 \mathrm{D}$ were analysed as in (b). Mean of three experiments performed in quadruplicates are shown for the viability assay $\left({ }^{* \star \star} P<0.0001\right)$. One representative experiment is shown for apoptosis analysis

TRAIL-sensitive SH-EP and SK-N-AS S-type NB cells (Figure $4 \mathrm{a}$ and Supplementary Information). Overexpression of caspase-10A and -10D strongly sensitised the cells to TRAIL, as compared with control cells (Figure 4b). In contrast, caspase-10B and -10G were not able to sensitise NB cells to TRAIL. On the opposite, a weak but significant protective effect of caspase-10G was observed in SH-EP (Figure 4b). In addition, caspase-10B and $G$ slightly increased SH-EP cells resistance to Fas-mediated cell death, while caspase-10A and $D$ were unable to induce Fas-sensitivity in NB cells. The enhanced TRAIL-mediated response induced by caspase-10A and $-D$ isoforms resulted from an increased induction of apoptosis (Figure 4c). Overexpression of caspase-10 isoforms did not affect the growth capacity of these cells (data not shown). In agreement with our data obtained in IGR-N-91 cells, these findings demonstrate that caspase-10B is unable to promote apoptosis while caspase-10A and -10D induce a significant pro-apoptotic signal on TRAIL but not Fas engagement in NB cells.

Caspase-10A and -10D have a pro-apoptotic role in colon (SW480) and B lymphoma (BJAB) cell lines. Apoptosis deregulations are often tumour-type specific. To determine whether the observed pro-apoptotic roles of caspase-10A and $-10 \mathrm{D}$ are restricted to NB cells, or observed in other tumour cell types, we overexpressed the four distinct caspase-10 isoforms in a colon carcinoma cell line, SW480 and in the B-cell lymphoma line BJAB (Figure 5a and Supplementary Information). As in NB cells, caspase$10 A$ and $-10 D$ strongly sensitised SW480 cells to TRAILmediated apoptosis, while caspase-10B and -10G showed 

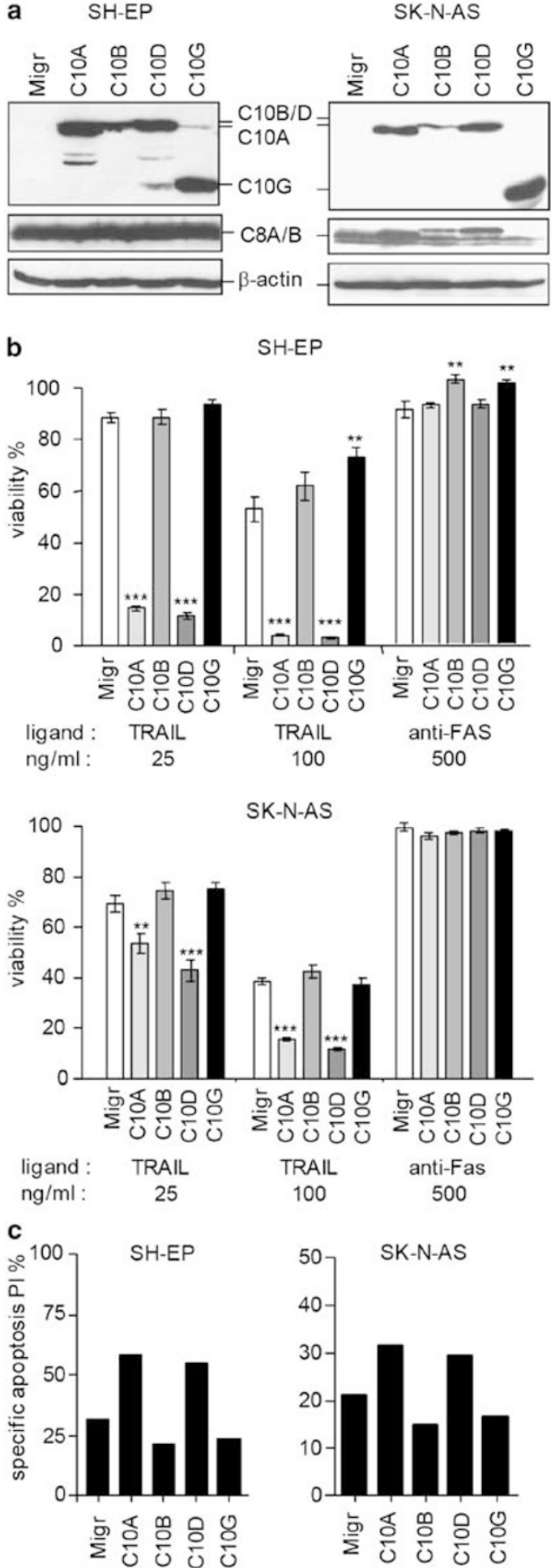

Figure 4 Caspase-10A and $-10 \mathrm{D}$ have a pro-apoptotic role in NB cells. (a) Immunoblotting analysis of caspase-10 and -8 expressions in SH-EP and SK-NAS cells transduced with the empty vector (Migr) or with vector encoding for C10A, C10B, C10D or C10G. (b) Cell viability of SH-EP and SK-N-AS transduced cells treated with the indicated doses of TRAIL and anti-Fas antibody for $48 \mathrm{~h}$. Mean of three experiments performed in quadruplicates are shown ${ }^{\star \star *} P<0.0001$, ${ }^{\star \star} P<0.005$ ). (c) Percentage of sub-G1 apoptotic cells after stimulation with $25 \mathrm{ng} / \mathrm{ml}$ of TRAIL for SH-EP and $100 \mathrm{ng} / \mathrm{ml}$ for SK-N-AS are indicated. A representative experiment is shown no sensitising effect (Figures $5 \mathrm{~b}$ and $\mathrm{c}$ ). Moreover, in contrast to NB cells, SW480 cells overexpressing caspase-10A and 10D became also highly sensitive to Fas stimulation (Figures $5 \mathrm{~b}$ and $\mathrm{c}$ ). Overexpression of caspase-10B resulted in a weak decrease in Fas-sensitivity in SW480 cells, as observed in SH-EP cells.

Similarly, overexpression of caspase-10A and -10D increased both, TRAIL and FasL sensitivity of the B lymphoma cell line BJAB (Figure 5c), while caspase-10G displayed an anti-apoptotic function, as observed in SH-EP cells.

Caspase-10A and -10D overexpression enhanced activation of the caspase-signalling cascade. To understand the mechanism by which caspase-10A and $10 \mathrm{D}$ potentiate apoptosis, the caspase-signalling cascade was analysed by immunoblotting and by colorimetric caspase assays. Caspase-10 showed strong proteolytic cleavage in SH-EP-C10A and -C10D treated with TRAIL, while no change in caspase-10B and only a very weak cleavage of caspase-10G were observed (Figure 6a). Caspase-8, Bid and caspase-9 were also more efficiently processed in SH-EP-C10A and SH-EP-C10D cells compared with SH-EP-Migr, -C10B or -C10G cells. The increase in Bid and caspase- 9 processing in SH-EP-C10A or $-\mathrm{C} 10 \mathrm{D}$ cells suggests an increased activation of the mitochondrial apoptotic pathway as well. Similar results were observed in SW480 cells (data not shown). Thus, overexpression of caspase-10A and -10D isoforms in two different tumour cell lines (SH-EP and SW480) resulted in enhanced downstream caspase-8, $-3,-2$ and -9 activities (Figure 6b), indicating that, unlike caspase-10B and -10G, caspase-10A and -10D stimulated the apoptotic-signalling cascade by enhancing caspases and Bid processing.

The $C$-terminal end of caspase-10B is responsible for its lack of activity in TRAIL and Fas sensitisation. We next interrogated why caspase-10B and -10G appeared either non-functional or having an opposite role compared with isoforms $A$ and $D$. The absence of the proteolytic domain in the caspase-10G isoform is sufficient to explain its inability to stimulate DR-induced apoptosis. In contrast, caspase-10B and $-10 \mathrm{D}$ isoforms are highly similar, as both isoforms contain the two additional exons (6 and 7) located at the $\mathrm{N}$-terminus of the large subunit of the proteolytic domain (p22) (Figure 1a). However, caspase-10B differs from caspase-10D and $-10 \mathrm{~A}$ by its C-terminal last 49 amino acids, resulting from an alternative splicing of the last coding exon, thus resulting in a different p12 subunit (Figure 1a). To determine if its $\mathrm{p} 12$ subunit is responsible for the differential activity of caspase-10B, a chimerical caspase-10A/B construct was generated by substituting the caspase-10A p12 fragment by that of caspase-10B (Figure 7a), and the resulting construct was transduced into the SW480 cells. Interestingly, caspase-10A/B, similarly to caspase-10B, became unable to increase TRAIL- and FasL-mediated apoptosis in SW480 cells (Figures $7 b$ and c). This indicates that the $C$-terminal end of caspase-10B is responsible for its specific lack of activity in TRAIL and Fas sensitisation.

To further analyse the mechanisms responsible for the lack of pro-apoptotic activity of caspase-10B, a time-course 
a

SW480
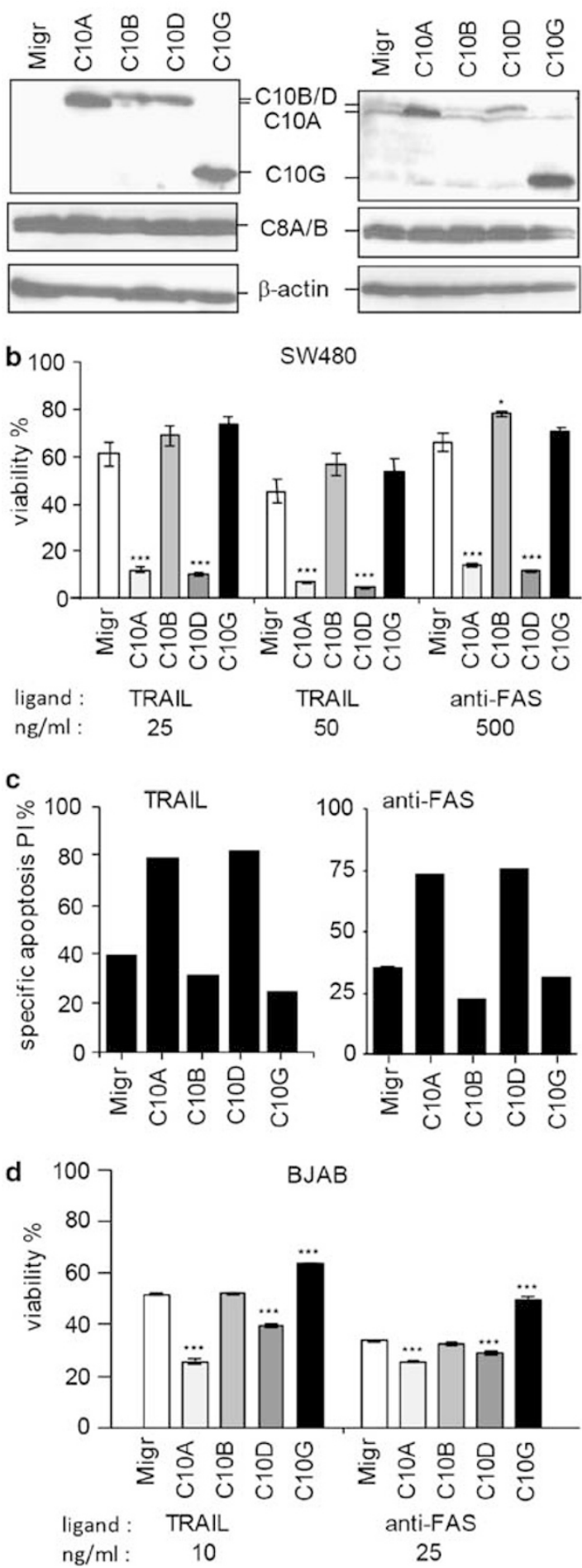

Figure 5 Caspase-10A and -10D have a pro-apoptotic role in SW480 and BJAB cell lines. (a) Immunoblotting analysis of caspase-10 and -8 expressions in SW480, or BJAB cells transduced with the empty Migr vector or with vector encoding for caspase-10A, -B, -D or -G. (b and d) Cell viability of SW480 (b), and BJAB (d) transduced cells treated with the indicated doses of TRAIL and anti-Fas antibody for $48 \mathrm{~h}$. Mean of three experiments performed in quadruplicates are shown $\left({ }^{\star \star *} P<0.0001,{ }^{\star} P<0.05\right)$. (c) Percentage of sub-G1 apoptotic cells after stimulation with $25 \mathrm{ng} / \mathrm{ml}$ of TRAIL and $500 \mathrm{ng} / \mathrm{ml}$ of anti-Fas antibody are indicated. A representative experiment is shown experiment for caspase activation was performed in SW480 cells. This revealed that SW480-C10A cells displayed a rapid processing of caspase- 10 within $2 \mathrm{~h}$, while no or very weak cleavage of caspase-10B or $-10 \mathrm{~A} / \mathrm{B}$ could be detected following stimulation with $50 \mathrm{ng} / \mathrm{ml}$ of TRAIL even at later time point (Figure 7d). Processing of caspase-8, Bid and caspase3 occurred with similar kinetics as caspase-10A processing in SW480-C10A cells, and was reduced and delayed in SW480C10B or $-\mathrm{C} 10 \mathrm{~A} / \mathrm{B}$ cells (Figure 7d). Interestingly, when SW480-C10B cells were exposed to higher TRAIL concentrations $(200 \mathrm{ng} / \mathrm{ml})$ full processing of caspase-10B, $-8,-3$ and Bid could nevertheless be achieved (Figure 7d, first lane), despite no increase in TRAIL sensitivity was observed (data not shown). This indicates that caspase-10B processing requires much higher doses of TRAIL than caspase-10A and $-10 D$ processing, and suggests that the unique sequence of the caspase-10B p12 subunit interferes with its efficient TRAIL-mediated activation.

Caspase-10B is a highly unstable caspase-10 isoform. To assess other possible causes for the differential behaviour of the distinct caspase-10 isoforms, their stability was measured using the protein synthesis inhibitor cycloheximide (CHX). Caspase$10 \mathrm{~B}$ and the chimeric caspase-10A/B isoforms were very rapidly degraded in SH-EP and SW480 cells with a strong reduction of their expression levels after 3 to $6 \mathrm{~h}$ of treatment. In contrast, caspase-10A, -D and -G, and caspase-8 were remarkably stable (Figure 8a).

We next investigated whether caspase-10B and $-10 A / B$ were degraded by the ubiquitin-proteasome pathway using the proteasome inhibitor lactacystin. Caspase-10B and -10A/ $\mathrm{B}$ were indeed protected from $\mathrm{CHX}$-mediated degradation by lactacystin treatment (Figure 8b). Collectively, these data suggest that the unique p12 fragment of caspase-10B destabilises the protein by promoting its proteasome-dependent degradation.

\section{Discussion}

In this study, we have investigated the participation of caspase-10 in TRAIL resistance of NB cells and described the specific role of individual caspase-10 isoforms in DR-mediated apoptosis in various human NB and adult tumour cell lines. We revealed a co-silencing of caspase-8 and -10 protein expression in $\mathrm{N}$-type cells, a sub-type of apoptosis-resistant NB cells. In contrast, TRAIL-sensitive Stype cells were shown to express both caspases. However, reduced levels of caspase-10 were detected in these cells as compared with normal primary cells (adrenal gland and PBL). Decreased caspase-10 expression was also shown in adult tumour cell lines, supporting previously reported decreased caspase-10 expression in transformed T- and B-cell lines. ${ }^{4}$ Moreover, we show that the absolute level of endogenous caspase-10 mRNA expression is significantly weaker than the level of caspase-8 mRNA in all cell types investigated, which suggests an independently controlled function for caspase-10.

ShRNA-mediated caspase-8 knock-down experiments in SH-EP cells clearly indicated that the low endogenous caspase-10 expression level in NB cells was not sufficient to 
a

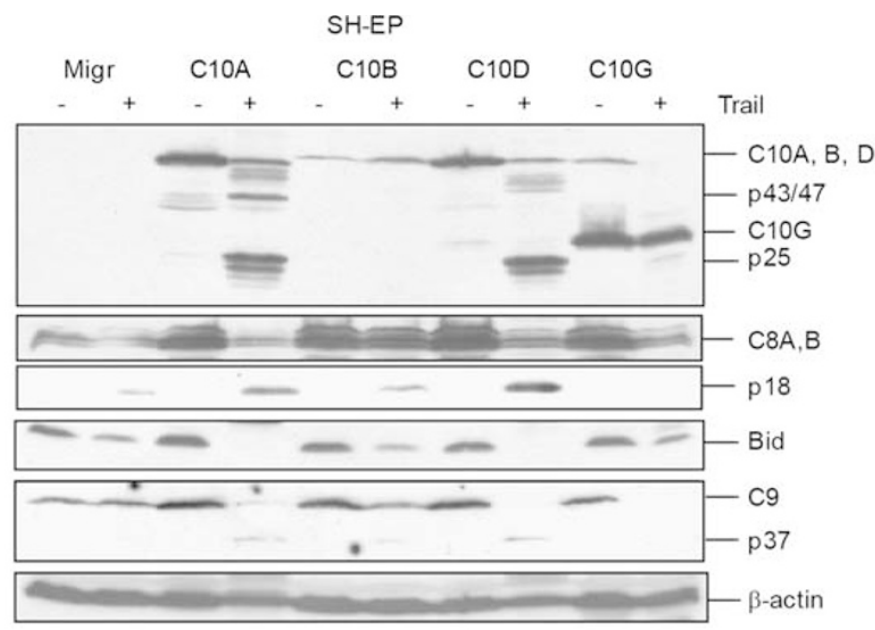

b

Caspase-8

Caspase-3

Caspase-9

Caspase-2
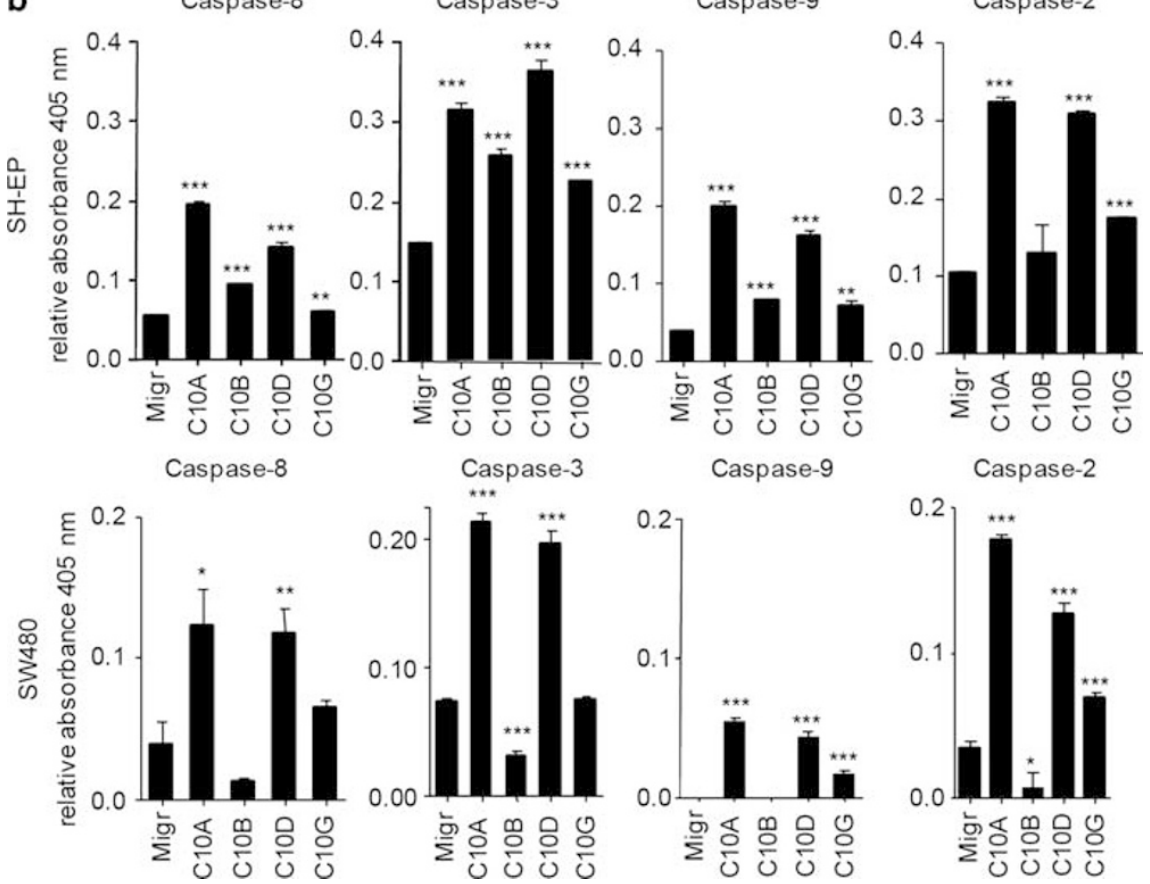

Figure 6 Caspase-10A and -10D overexpression enhances the caspase cascade activation. (a) Immunoblotting analysis of caspases-10, $-8,-9$, and Bid cleavage in cells untreated or treated with $50 \mathrm{ng} / \mathrm{ml}$ of TRAlL for $16 \mathrm{~h}$. (b) Caspase activity was measured in cell lysates from SH-EP (upper panels) and SW480 (lower panels) transduced cells treated with $50 \mathrm{ng} / \mathrm{ml}$ TRAIL for $8 \mathrm{~h}$ or $25 \mathrm{ng} / \mathrm{ml}$ of TRAIL for $16 \mathrm{~h}$, respectively. Relative OD at $405 \mathrm{~nm}$ of stimulated compared with unstimulated cells of two experiments performed in duplicates are represented $\left({ }^{* *} P<0.0001,{ }^{* *} P<0.001,{ }^{*} P<0.05\right)$

initiate an apoptotic cascade, even in the presence of a weak amount of residual caspase-8. Cell sensitivity to DR stimulation was shown to be directly dependent on initiator caspases expression levels. Indeed, TRAIL sensitivity of IGR-N-91 cells restored for caspase-8 expression was directly dependent on caspase-8 expression levels. ${ }^{27}$ Similarly, FasL sensitivity of caspase-8-deficient Jurkat 19-2 cells was shown to correlate with endogenous caspase- 10 content. ${ }^{5}$ Moreover, the induction of caspase-8 or -10 expression in NB cells using either demethylating agent or IFN- $\gamma$ resulted in enhanced cellular sensitivity to death ligands. ${ }^{25,28-30}$ Altogether, these findings indicate that not only caspase-8, but also caspase-10 levels need to be tightly controlled, and that caspase-10 down- regulation is likely to significantly influence and modulate NB cells sensitivity to DR-induced apoptosis.

In addition to the demonstration of a co-silencing of initiator caspases related to aggressive and apoptosis-resistant NB tumours cells, our data identified a reduced level of both initiator caspases expression in adult tumour cells. This feature, which was linked to a correspondingly decreased sensitivity to DR-mediated cell death, is likely to represent a general mechanism of resistance to cell death developed by tumour cells.

Caspase-10 silencing was previously reported to occur by post-transcriptional control in adult and paediatric tumour cells. $^{15,19}$ Our data, in contrast, indicate that caspase-10 


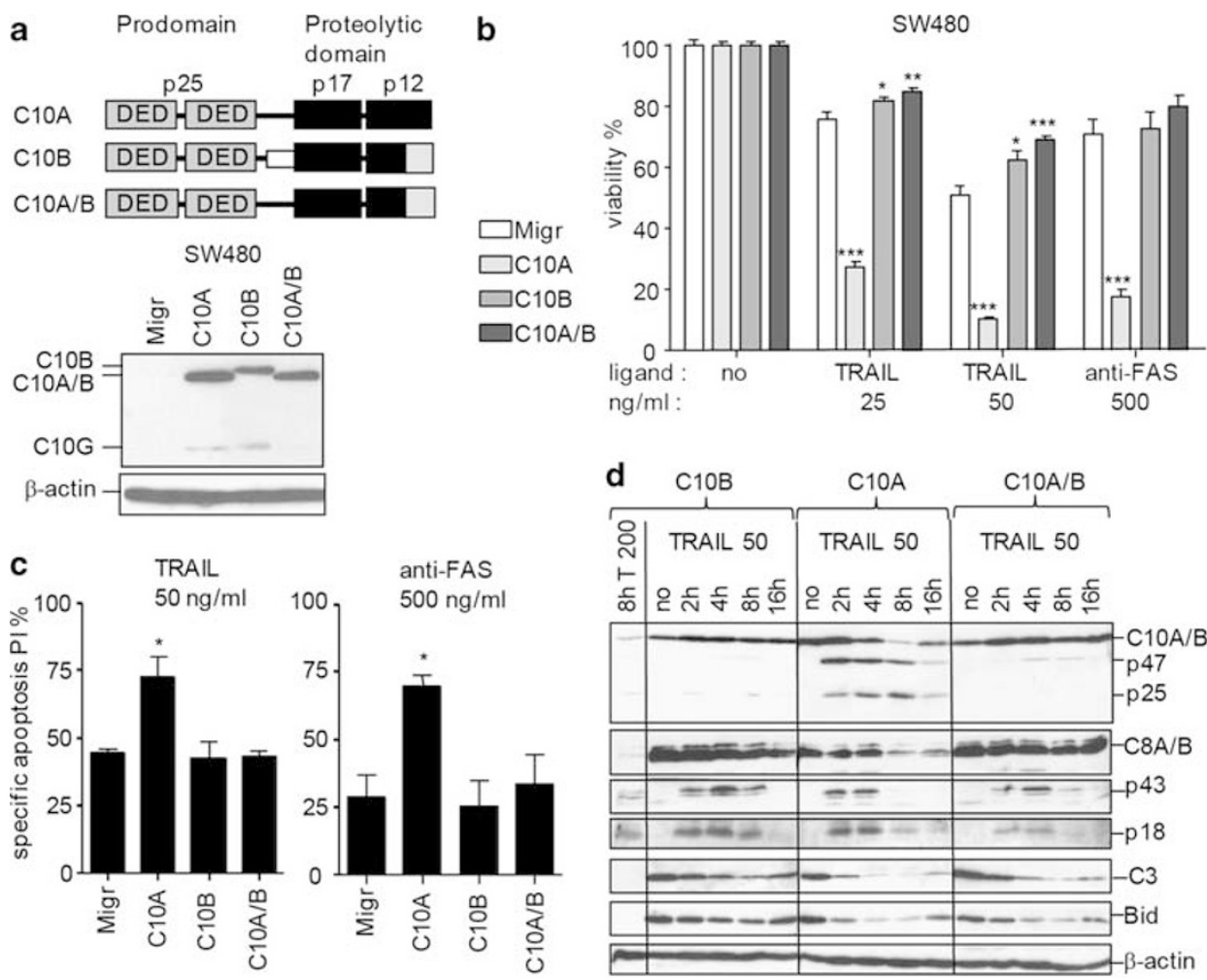

Figure 7 The $C$-terminal end of caspase-10B is responsible for its lack of activity in TRAIL and Fas sensitisation. (a) Up: schematic representation of the C10A/B fusion protein. Down: whole cell extracts from SW480-Migr, -C10A, - C10B or -C10A/B cells were analysed by immunoblotting for the presence of caspase-10 and $\beta$-actin. (b) Cell viability measured in SW480 cells treated with the indicated doses of TRAIL and anti-Fas antibody for $48 \mathrm{~h}$. Mean of two experiments performed in quadruplicates are shown $\left({ }^{\star \star \star} P<0.0005,{ }^{\star \star} P<0.005,{ }^{*} P<0.05\right)$. (c) Percentage of sub-G1 apoptotic cells after stimulation with $50 \mathrm{ng} / \mathrm{ml}$ of TRAlL and $500 \mathrm{ng} / \mathrm{ml}$ of anti-Fas antibody are indicated. Mean of two experiments are shown $\left({ }^{*} P<0.05\right)$. (d) Whole cell extracts from SW480-C10A, $-\mathrm{C} 10 \mathrm{~B},-\mathrm{C} 10 \mathrm{~A} / \mathrm{B}$ cells, untreated or treated with $50 \mathrm{ng} / \mathrm{ml}$ of TRAIL for various time length, or with $200 \mathrm{ng} / \mathrm{ml}$ of TRAIL for $8 \mathrm{~h}$, were analysed by immunoblotting for the cleavage of caspases $-10,-8,-3$, and Bid

silencing in NB cells essentially occurs at the transcriptional level, as the relatively low amounts of caspase-10 mRNA measured by real-time PCR directly correlated with protein expression measured by immunoblotting in $\mathrm{N}$ - and S-type cells. This is compliant with studies showing that caspase-10 mRNA expression in TRAIL-resistant NB cells could be restored by the methyltransferase inhibitor $5-A D C .{ }^{28}$

To address more specifically the function of caspase-10 in TRAIL or FasL-mediated cell death in tumour cells, we have explored the role of individual caspase-10 isoforms. Stable caspase-10A or -10D overexpression in caspase-8positive SH-EP, SK-N-AS, SW480 and BJAB cells displayed a strong pro-apoptotic activity on TRAIL stimulation. Although caspase-10A or $-10 D$ only sensitise SW480 and BJAB cells to Fas stimulation, NB cells remained resistant because of their minimal Fas and high FLIP expression levels. ${ }^{25,31}$ In addition, stable overexpression of caspase-10A or -10D isoforms in caspase-8/-10-silenced NB cells resulted in restoration of TRAIL sensitivity, indicating that, when expressed at sufficient levels, caspase-10A and -D isoforms are fully functional and can substitute for caspase- 8 in TRAIL-mediated apoptosis in NB cells, as reported for Jurkat 19-2 cells. ${ }^{15}$ Our results also show that caspase-8 and -10 can initiate apoptosis independently of each other in NB cells.

When stably overexpressed, caspase-10B and -10G isoforms, in contrast, were either non-functional or even displayed anti-apoptotic activity. Caspase-10G resembles caspase-8L in lacking the active proteolytic domain, but retains the two DEDs. Our results suggest that, depending on the cellular context, caspase-10G may be either inactive (SK$\mathrm{N}-\mathrm{AS}, \mathrm{SW} 480$ ) or act as a dominant-negative inhibitor of apoptosis (SH-EP, BJAB). In this case, caspase-10G is likely to interfere, like caspase-8L or viral FLIP proteins, with the recruitment of endogenous initiator caspases to activated receptors. $^{32,33}$ The differential pro- or anti-apoptotic activity of caspase-10A and -D and caspase-10B and -G, respectively, was observed in all tumour cell lines analysed, indicating that the opposing properties of caspase-10 isoforms are not restricted to NB. Nevertheless, caspase-10B was previously shown to have a pro-apoptotic activity in MCF-7 overexpressing exogenous caspase-3 (ref. 34).

Interestingly, the inactive or anti-apoptotic caspase-10B isoform is highly homologous to the pro-apoptotic caspase$10 \mathrm{D}$ isoform, except for the last 49 amino acids that generate a caspase-10B-specific p12 fragment. The generation of a chimeric protein caspase-10A/B allowed us to demonstrate that the differential activity of caspase-10B resulted from its unique $C$-terminal end, which also mediated its destabilisation via the proteasome pathway. When exogenously expressed, caspase-10B protein level was always weaker than that of other caspase-10 isoforms. This was most likely the result of its weaker stability, as caspase-10B mRNA expression level was higher than that of caspase-10A, -10D or -10G mRNAs 
a

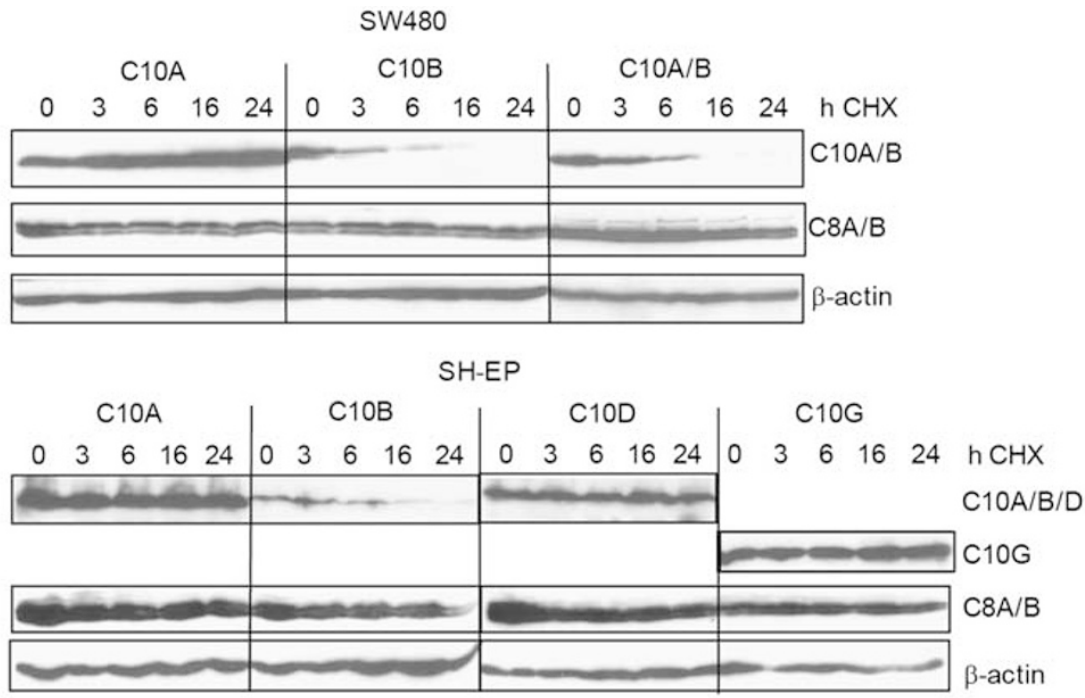

b

SW480

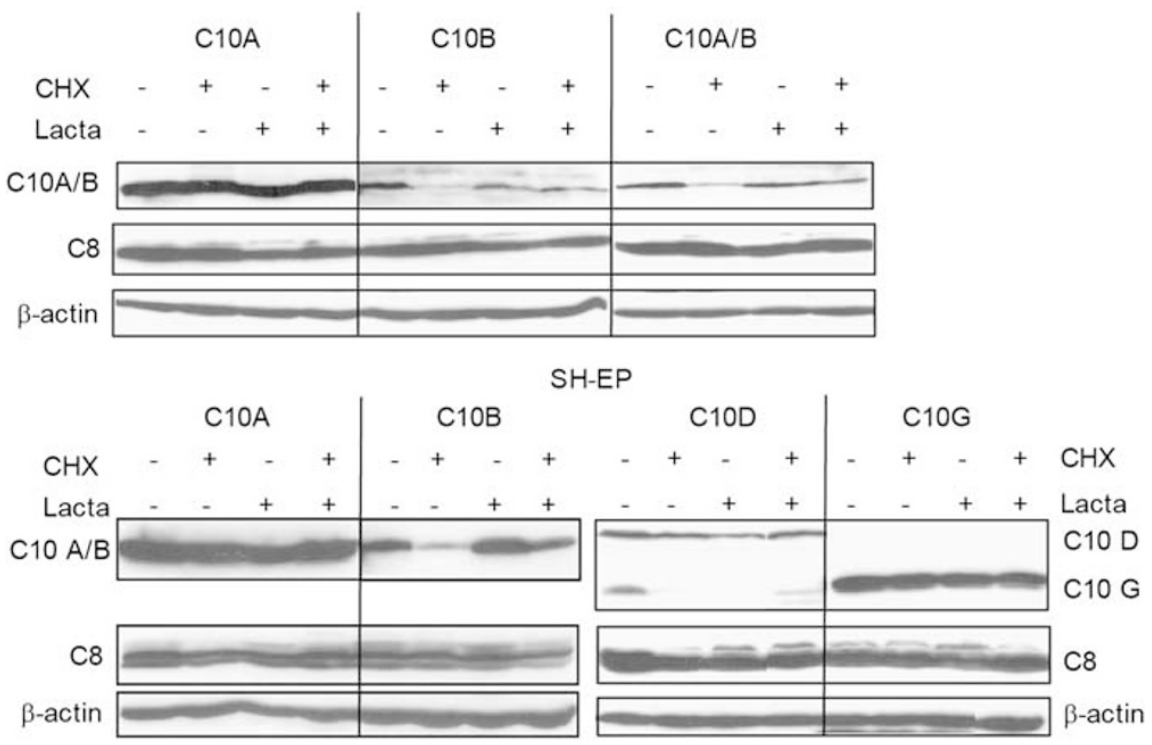

Figure 8 Caspase-10B is highly unstable, in contrast to other caspase-10 isoforms. (a) Whole cell extracts from SW480 and SH-EP cells overexpressing the indicated caspase-10 isoforms, untreated or treated with $20 \mathrm{ug} / \mathrm{ml}$ of $\mathrm{CHX}$ for various times, were analysed by immunoblotting for the presence of caspases-10, -8 and $\beta$-actin. (b) Whole cell extracts from SW480 and SH-EP-infected cells untreated or treated with $20 \mathrm{ug} / \mathrm{ml}$ of $\mathrm{CHX}$, with or without lactacystin ( $10 \mu \mathrm{M}$ for SH-EP or $50 \mu \mathrm{M}$ for SW480) for $16 \mathrm{~h}$, were analysed as in (a)

(Supplementary Information). Interestingly, analysis of the caspase-10B amino acid sequence (using Conserved Domains search service from $\mathrm{NCBI}$ ) revealed that several amino acids involved in the protease dimer interface are lacking in caspase-10B p12 subunit, as compared with caspase-10A, -10D or -8. As dimerisation of apical caspases is crucial for their activation, ${ }^{35}$ the formation of less stable dimers could result in a reduced ability of caspase-10B to be auto-activated or to a weaker proteolytic activity. Indeed, caspase-10A and -D were very quickly activated on TRAIL exposure, while caspase-10B activation needed increased amounts of TRAIL. Interestingly, caspase-10B exhibited a short half-live, since its basal expression level could be enhanced by the proteasome inhibitor Lactacystin in SH-EP and SW480 cells, in contrast to other caspase-10 isoforms or caspase-8. Interestingly the steady-state levels of other DISC components, such as Trail-R2 and FLIP, have also been shown to be modulated by the proteasome pathway via ubiquitination. ${ }^{36,37}$

In conclusion, our results obtained with a panel of NB and adult tumour cell lines uncovered an important (critical) role for caspase-10 in the initiation of DR apoptosis. A differential proor anti-apoptotic role for distinct caspase-10 isoforms was revealed. Moreover, our data revealed the transcriptional silencing of caspase-10 in tumour, such as NB as an essential mechanism of resistance to DR signalling. In tumour as in normal cells, the balance in the relative expression of initiator caspases- 8 and -10 isoforms may thus provide an additional keen (subtle) regulatory mechanism of tumour sensitisation to apoptotic stimuli. Identification of therapeutic strategies 
capable to differentially modulate the expression of particular caspase-10 isoforms would help in the further sensitisation of highly apoptosis-resistant tumours such as NB.

\section{Materials and Methods}

Cell culture and reagent. The NB cell lines and the colon carcinoma cell line SW480 were grown in DMEM medium, and Jurkat, Ramos, Hut78, CEM and BJAB cells were grown in RPMI medium. The media were supplemented with $2 \mathrm{mM}$ L-glutamine, $100 \mathrm{U} / \mathrm{ml}$ penicillin, $0.1 \mathrm{mg} / \mathrm{ml}$ streptomycin and $10 \%$ of FCS. Cells were treated with the indicated amount of recombinant Flag-TRAIL (a gift from $\mathrm{J}$ Tschopp, Enzo Life Sciences, Lausen, Switzerland) and cross-linking mouse antiFlag Ab M2 (Sigma-Aldrich, Buchs, Switzerland) with a constant ratio of 1/5 of TRAIL to M2 respectively, or with anti-Fas antibody (CH11, Millipore, Zug Switzerland). Cells were treated simultaneously with $\mathrm{CHX}$ (Sigma) and with Lactacystin (Alexis Biochemicals) when indicated.

Cell viability assays. Cells $\left(1-2.5 \times 10^{4}\right.$ per well in 96-well plates; $\left.100 \mu \mathrm{l}\right)$ were plated $24 \mathrm{~h}$ before treatment and incubated with TRAIL/M2 or anti-Fas antibody for $48 \mathrm{~h}$. Assays were performed in quadruplicates. Viability was measured using the MTS/PMS cell proliferation kit from Promega AG (Wallisellen, Switzerland) according to the manufacturer's instructions. Percentage of cell viability as compared with untreated controls was calculated.

Measurement of apoptosis by detection of sub-diploid population. Cells were treated in six wells with TRAIL/M2 or anti-Fas antibody for $48 \mathrm{~h}$, harvested by trypsinisation and washed twice with ice-cold PBS, suspended in $1 \mathrm{ml}$ of ice-cold PBS and fixed with $3 \mathrm{ml}$ of $100 \%$ ice-cold ethanol for $1 \mathrm{~h}$ at $4{ }^{\circ} \mathrm{C}$. For staining with propidium iodide $(\mathrm{PI})$, cells were washed twice in ice-cold PBS, suspended in $0.2 \mathrm{ml}$ of PBS containing $200 \mu \mathrm{g} / \mathrm{ml} \mathrm{RNaseA}$ and $10 \mu \mathrm{g} / \mathrm{ml} \mathrm{PI}$, and incubated for $30 \mathrm{~min}$ at room temperature. The stained cells were analysed using a FACScan flow cytometer (Becton Dickinson, Allschwil, Switzerland).

Immunoblotting. Cells were homogenised in lysis buffer $(50 \mathrm{mM}$ Tris- $\mathrm{HCl}$ $\mathrm{pH} 7.4,150 \mathrm{mM} \mathrm{NaCl}, 1 \%$ Triton-X100, $1 \mathrm{mM}$ EDTA and protease inhibitor cocktail (Sigma)) on ice for $15 \mathrm{~min}$ with shaking, and spin at $12000 \times g$ at $4^{\circ} \mathrm{C}$ for $15 \mathrm{~min}$ to recover the supernatant representing the whole cell extracts. Protein extracts $(50 \mu \mathrm{g})$ were loaded on SDS-PAGE and transferred on nitrocellulose membranes. Blots were saturated with $5 \%$ skim milk, $0.1 \%$ Tween 20 in TBS and revealed using mouse monoclonal antibodies to detect caspase-8, -10 (MBL, Nunningen, Switzerland) caspase-3 and $\beta$-actin (Sigma). Polyclonal rabbit antibodies were used to detect caspase-9 (Cell Signaling Technology, Danver, MA, USA), Bid, (BD Transduction Laboratories, Allschwill, Switzerland). Binding of the first antibody was revealed by incubation with either goat anti-mouse IgG-HRP (Jackson ImmunoResearch, Suffolk, UK) or goat anti-rabbit IgG-HRP (Nordic Immunological Laboratories, Tilburg, Netherlands). Bound antibodies were detected using the Lumi-light (Roche, Rotkreuz, Switzerland) or the ECL Advanced (GE Healthcare, Glattbrugg, Switzerland) western blotting substrates according to the manufacturer's instructions. $\beta$-actin signal was used as loading control.

Caspases activities. Caspases- $8,-2,-3$ and -9 protease activities were measured using the caspases colorimetric protease assay kits from Biovision (Mountain View, CA, USA) and the colorimetric substrate Ac-DEVD-pNA (Biovision), Ac-VDVAD-pNA, Ac-IETD-pNA and Ac-LEHD-pNA (Alexis Biochemicals). Cytosolic lysates were prepared after TRAIL treatments according to the manufacturer's instructions. Forty $\mu \mathrm{g}$ of protein extracts were incubated with $200 \mu \mathrm{M}$ of colorimetric substrates for $3 \mathrm{~h}$ at $37^{\circ} \mathrm{C}$ in 384 -well plates in a total volume of $20 \mu \mathrm{l}$. Cell lysates were incubated with $10 \mu \mathrm{M}$ of the pan-caspase inhibitor (zVDAD-fmk, Bachem, Bubendorf, Switzerland) for $30 \mathrm{~min}$ before addition of the respective caspase substrate for the inhibited caspases condition. Hydrolysed pNA was detected using a microtitre plate reader at $405 \mathrm{~nm}$. Background absorbance from cell lysates and buffers were subtracted from the absorbance of stimulated and unstimulated samples before calculation of the relative absorbance. Relative absorbance was calculated as the following: $\left(A_{405}\right.$ of induced sample- $A_{405}$ of negative control sample $)-\left(A_{405}\right.$ of inhibited caspases sample- $A_{405}$ of negative control sample).
Construction of caspase-10 expression vectors. CDNA from SH-EP and Jurkat cells were produced using Superscript reverse transcriptase II (Invitrogen, Basel, Switzerland) according to the manufacturer's instructions. Capase-10 isoforms were obtained by PCR using isoform-specific primers. PCR products were digested by $E c o R_{1}$ and inserted into the $E c o R_{\mid}$site of the pCR3.1 plasmid. All the caspase10-pCR3 vectors were digested by $B a m H_{1}$ and $X h O_{1}$ to insert a FLAG-tag at the $\mathrm{N}$-terminus of the $\mathrm{C} 10$ protein isoforms, and the FLAG-C10 DNA fragments were inserted into the pMIGR1 vector into $B g l_{\| 1}-X h O_{1}$ sites. All the caspase-10 expression vectors were verified by DNA sequencing.

Overexpression experiments. Cells were infected with a biscistronic retroviral vector encoding for the GFP gene and a specific caspase-10 isoform, or with the GFP control vector (Migr) as described previously. ${ }^{27}$ The cells were then kept under standard cell culture conditions for 2 weeks, and the GFP-expressing cell population was selected for each cell line using a FACSAria Cell Sorter (Becton Dickinson), except for IGR-N-91 cells, which were cloned. Several transduced IGR-N-91 clones were selected for the highest caspase-10 expression by immunoblotting, and eventually pooled for further analysis.

Sh/siRNA-mediated silencing experiments. Stable downregulation of caspase-8 was achieved by RNA interference using short hairpin as described. ${ }^{31,38}$ Transient downregulation of caspase- 10 and -8 was performed using HiPerFect transfection reagent (Qiagen, Basel, Switzerland) according to the manufacturer's instructions. Briefly, 200000 cells per well were plated in 12 wells in $1.1 \mathrm{ml}$ of medium and transfected $8 \mathrm{~h}$ later with $20 \mathrm{nM}$ of siRNAs and $9 \mu \mathrm{l}$ of HiPerFect. At $16 \mathrm{~h}$ after transfection, cells were plated in 96 wells ( 10000 cells per well) and induced with TRAIL for $48 \mathrm{~h}$. For RNA analysis cells were harvested $24 \mathrm{~h}$ after transfection and RNAs were isolated using the RNeasy mini kit (Qiagen). The siRNA for $\mathrm{C} 10$ was localised in a common exon to efficiently silence all caspase-10 isoforms (siRNA Hs_CASP10_2, Qiagen). For specific caspase-10 isoform silencing, specific siRNAs were designed using the siDesign Center program from Dharmacon (Lafayette, CO, USA). Nevertheless, C10A and C10D cannot be separately downregulated. The target sequences are the following: siRNA-C10A/D $5^{\prime}$ GACAAACAGGGAACAAAGAAA-3', siRNA-C10B 5'-TCTGGAAAAGACAATGGAAA T-3', siRNA-C10G 5'-ACCGTGGAAACTCGCCAGATG-3'. The negative control siRNA is the AllStars Neg siRNA AF488 from Qiagen.

RNA preparation and semi-quantitative real-time RT-PCR. Total RNA from NB cell lines was extracted from $1 \times 10^{6}$ cells using the RNeasy Mini kit, according to the manufacturer's instructions (Qiagen). Five hundred nanograms were reverse transcribed using the PrimeScript RT reagent Kit (TAKARA Bio, St Germain en Laye, France) using random primers and oligo dT primers according to the manufacturer's instructions. The expression levels of caspase- 8 and -10 were assessed by real-time quantitative RT-PCR using the Corbett Rotor-Gene 6000 real-time cycler (Qiagen) with SYBR green technology. A standard curve was performed for caspase-8, -10 and HPRT1 with serial dilutions of a reference CDNA to insure that the amplification efficiencies were comparable. The expression levels of the caspase- 8 and -10 transcripts in each cell line were reported to the level of the housekeeping gene HPRT1. The sequences of specific primers are the following: caspase-8 forward 5'-ATGCAAACTGGATGATGACA-3', and reverse $5^{\prime}$-TTCAT TATCTTCAGCAGGCTC-3', caspase-10 all mRNAs forward: 5'-AATCTGA CATGCCTGGAG- $3^{\prime}$, and reverse: $5^{\prime}$-ACTCGGCTTCCTTGTCTAC- ${ }^{\prime}$, C10A and C10D forward: $5^{\prime}$-TGGTCCCAAGACATGAAGACA-3', and reverse: $5^{\prime}$-CCAGGGG CACAGGGAATAC-3', C10B forward 5'-CAGGACAGTATTCCTGCCGA-3', and reverse 5'-ATTTCAGCATCCTTGGGACC-3', C10G forward 5'-GAGAGGAAGAACTAGTTC CC-3', and reverse $5^{\prime}$-ATCTGGCGAGTTTCCACGG-3'. The amplified products are 138, 124, 147, 148 and 107 bp long, respectively. Specific oligos for HPRT1 were already described ${ }^{39}$ and amplified a 93-bp PCR fragment. The real-time semi-quantitative PCR was performed using the KAPA SYBR FAST qPCR kit (KAPA Biosystems, Boston, MA, USA) in the presence of $0.2 \mu \mathrm{M}$ sense and antisense primers. The cycling conditions comprised 3 min polymerase activation at $95^{\circ} \mathrm{C}$, followed by 40 cycles of $3 \mathrm{~s}$ at $95^{\circ} \mathrm{C}, 20 \mathrm{~s}$ at $60^{\circ} \mathrm{C}$ and $1 \mathrm{~s}$ at $72^{\circ} \mathrm{C}$ for fluorescence acquisition. The expression levels of three independent experiments evaluating the expression levels of caspase-8 and -10 transcripts for each cell line were calculated relative to the level of the housekeeping gene HPRTI. The ratio of caspase-8 or -10 to HPRT1 gene expression was evaluated using the $\Delta$ Ct method 
Statistical analysis. Statistical significance of the results was analysed using Student's unpaired two-tailed $t$-test with subsequent Welch correction using GraphPad Prism 4.03 software (La Jolla, CA, USA).

\section{Conflict of interest}

The authors declare no conflict of interest.

Acknowledgements. We thank $J$ Tschopp for providing us with TRAIL, $\mathrm{M}-\mathrm{C}$ Osterheld for giving us the adrenal gland, V Combaret for giving us the CLBBer-Lud1/2 cells and A Nahimana for providing us with PBL. We also thank J-E Charton for technical help and discussions and R Meier for critical review of the paper. This work was supported by grants from the Emma Muschamp and FORCE Foundations.

1. Hanahan D, Weinberg RA. The hallmarks of cancer. Cell 2000; 100: 57-70.

2. Hengartner MO. The biochemistry of apoptosis. Nature 2000; 407: 770-776.

3. Fulda S. Caspase-8 in cancer biology and therapy. Cancer Lett 2009; 281: 128-133.

4. Wang J, Chun HJ, Wong W, Spencer DM, Lenardo MJ 2001 Caspase-10 is an initiator caspase in death receptor signaling. Proc Natl Acad Sci USA 98: 13884-13888.

5. Milhas D, Cuvillier O, Therville N, Clave P, Thomsen M, Levade T et al. Caspase-10 triggers Bid cleavage and caspase cascade activation in FasL-induced apoptosis. $\mathrm{J} \mathrm{Biol}$ Chem 2005; 280: 19836-19842.

6. Von Haefen C, Wieder T, Essmann F, Schulze-Osthoff K, Dorken B, Daniel PT. Paclitaxelinduced apoptosis in BJAB cells proceeds via a death receptor-independent, caspases-3/8-driven mitochondrial amplification loop. Oncogene 2003; 22: 2236-2247.

7. Filomenko R, Prevotat L, Rebe C, Cortier M, Jeannin JF, Solary E et al. Caspase-10 involvement in cytotoxic drug-induced apoptosis of tumor cells. Oncogene 2006; 25: 7635-7645.

8. Park SJ, Wu CH, Gordon JD, Zhong X, Emami A, Safa AR. Taxol induces caspase-10dependent apoptosis. J Biol Chem 2004; 279: 51057-51067.

9. Lee HJ, Pyo JO, Oh Y, Kim HJ, Hong SH, Jeon YJ et al. AK2 activates a novel apoptotic pathway through formation of a complex with FADD and caspase-10. Nat Cell Biol 2007; 9: 1303-1310.

10. Grenet J, Teitz T, Wei T, Valentine V, Kidd VJ. Structure and chromosome localization of the human CASP8 gene. Gene 1999; 226: 225-232.

11. Fernandes-Alnemri T, Armstrong RC, Krebs J, Srinivasula SM, Wang L, Bullich F et al. In vitro activation of CPP 32 and Mch3 by Mch4, a novel human apoptotic cysteine protease containing two FADD-like domains. Proc Natl Acad Sci USA 1996; 93: 7464-7469.

12. Ng PW, Porter AG, Janicke RU. Molecular cloning and characterization of two novel proapoptotic isoforms of caspase-10. J Biol Chem 1999; 274: 10301-10308.

13. Wang $H$, Wang $P$, Sun $X$, Luo $Y$, Wang $X, M a ~ D$ et al. Cloning and characterization of a novel caspase-10 isoform that activates NF-kappa B activity. Biochim Biophys Acta 2007; 1770: 1528-1537.

14. Vincenz C, Dixit VM. Fas-associated death domain protein interleukin-1beta-converting enzyme 2 (FLICE2), an ICE/Ced-3 homologue, is proximally involved in. J Biol Chem 1997; 272: $6578-6583$.

15. Kischkel FC, Lawrence DA, Tinel A, LeBlanc H, Virmani A, Schow $P$ et al. Death receptor recruitment of endogenous caspase-10 and apoptosis initiation in the absence of caspase8. J Biol Chem 2001; 276: 46639-46646.

16. Sprick MR, Rieser E, Stahl H, Grosse-Wilde A, Weigand MA, Walczak H. Caspase-10 is recruited to and activated at the native TRAIL and CD95 death-inducing signalling complexes in a FADD-dependent manner but cannot functionally substitute caspase-8. EMBO J 2002; 21: 4520-4530.

17. Shin MS, Kim HS, Kang CS, Park WS, Kim SY, Lee SN et al. Inactivating mutations of CASP10 gene in non-Hodgkin lymphomas. Blood 2002; 99: 4094-4099.

18. Park WS, Lee JH, Shin MS, Park JY, Kim HS, Lee JH et al. Inactivating mutations of the caspase-10 gene in gastric cancer. Oncogene 2002; 21: 2919-2925.

19. Harada K, Toyooka S, Shivapurkar N, Maitra A, Reddy JL, Matta H et al. Deregulation of caspase 8 and 10 expression in pediatric tumors and cell lines. Cancer Res. 2002; 62 : 5897-5901.

20. Shin MS, Kim HS, Lee SH, Lee JW, Song YH, Kim YS et al. Alterations of Fas-pathway genes associated with nodal metastasis in non-small cell lung cancer. Oncogene 2002; 21: 4129-4136.

21. Fischer U, Stroh $C$, Schulze-Osthoff K. Unique and overlapping substrate specificities of caspase-8 and caspase-10. Oncogene 2006; 25: 152-159.

22. Wachmann K, Pop C, van Raam BJ, Drag M, Mace PD, Snipas SJ et al. Activation and specificity of human caspase-10. Biochemistry 2010; 49: 8307-8315.

23. Brodeur GM. Neuroblastoma: biological insights into a clinical enigma. Nat Rev Cancer 2003; 3: 203-216.

24. Teitz T, Wei T, Valentine MB, Vanin EF, Grenet J, Valentine VA et al. Caspase 8 is deleted or silenced preferentially in childhood neuroblastomas with amplification of MYCN. Nat Med 2000; 6: 529-535.

25. Hopkins-Donaldson S, Bodmer JL, Bourloud KB, Brognara CB, Tschopp J, Gross N. Loss of caspase- 8 expression in highly malignant human neuroblastoma cells correlates with resistance to tumor necrosis factor-related apoptosis-inducing ligand-induced apoptosis. Cancer Res 2000; 60: 4315-4319.

26. La Quaglia MP, Manchester KM. A comparative analysis of neuroblastic and substrateadherent human neuroblastoma cell lines. J Pediatr Surg 1996; 31: 315-318.

27. Muhlethaler-Mottet A, Bourloud KB, Auderset K, Joseph JM, Gross N. Drug-mediated sensitization to TRAIL-induced apoptosis in caspase-8-complemented neuroblastoma cells proceeds via activation of intrinsic and extrinsic pathways and caspase-dependent cleavage of XIAP, Bcl-x(L) and RIP. Oncogene 2004; 23: 5415-5425.

28. Eggert A, Grotzer MA, Zuzak TJ, Wiewrodt BR, Ho R, Ikegaki N et al. Resistance to tumor necrosis factor-related apoptosis-inducing ligand (TRAIL)-induced apoptosis in neuroblastoma cells correlates with a loss of caspase-8 expression. Cancer Res 2001; 61: $1314-1319$.

29. Fulda S, Kufer MU, Meyer E, van VF, Dockhorn-Dworniczak B, Debatin KM. Sensitization for death receptor- or drug-induced apoptosis by re-expression of caspase-8 through demethylation or gene transfer. Oncogene 2001; 20: 5865-5877.

30. Yang X, Merchant MS, Romero ME, Tsokos M, Wexler LH, Kontny $U$ et al. Induction of caspase 8 by interferon gamma renders some neuroblastoma (NB) cells sensitive to tumor necrosis factor-related apoptosis-inducing ligand (TRAIL) but reveals that a lack of membrane TR1/TR2 also contributes to TRAIL resistance in NB. Cancer Res 2003; 63: 1122-1129.

31. Flahaut M, Muhlethaler-Mottet A, Auderset K, Bourloud KB, Meier R, Popovic MB et al. Persistent inhibition of $F L I P(L)$ expression by lentiviral small hairpin RNA delivery restores death-receptor-induced apoptosis in neuroblastoma cells. Apoptosis 2006; 11: 255-263.

32. Himeji D, Horiuchi T, Tsukamoto H, Hayashi K, Watanabe T, Harada M. Characterization of caspase-8L: a novel isoform of caspase-8 that behaves as an inhibitor of the caspase cascade. Blood 2002; 99: 4070-4078.

33. Thome M, Schneider P, Hofmann K, Fickenscher H, Meinl E, Neipel F et al. Viral FLICEinhibitory proteins (FLIPs) prevent apoptosis induced by death receptors. Nature 1997; 386: 517-521.

34. Engels IH, Totzke G, Fischer U, Schulze-Osthoff K, Janicke RU. Caspase-10 sensitizes breast carcinoma cells to TRAIL-induced but not tumor necrosis factor-induced apoptosis in a caspase-3-dependent manner. Mol Cell Biol 2005; 25: 2808-2818.

35. Boatright KM, Renatus M, Scott FL, Sperandio S, Shin H, Pedersen IM et al. A unified model for apical caspase activation. Mol Cell 2003; 11: 529-541.

36. Johnson TR, Stone K, Nikrad M, Yeh T, Zong WX, Thompson CB et al. The proteasome inhibitor PS-341 overcomes TRAIL resistance in Bax and caspase 9-negative or $\mathrm{Bcl}-\mathrm{xL}$ overexpressing cells. Oncogene 2003; 22: 4953-4963.

37. Poukkula M, Kaunisto A, Hietakangas V, Denessiouk K, Katajamaki T, Johnson MS et al. Rapid turnover of C-FLIPshort is determined by its unique C-terminal tail. J Biol Chem 2005; 280: 27345-27355.

38. Raguenez G, Muhlethaler-Mottet A, Meier R, Duros C, Benard J, Gross N. Fenretinideinduced caspase-8 activation and apoptosis in an established model of metastatic neuroblastoma. BMC Cancer 2009; 9: 97.

39. Vandesompele J, De PK, Pattyn F, Poppe B, Van RN, De PA et al. Accurate normalization of real-time quantitative RT-PCR data by geometric averaging of multiple internal control genes. Genome Biol 2002; 3: RESEARCH0034.

40. Anderson CW, Baum PR, Gesteland RF. Processing of adenovirus 2-induced proteins. $J$ Virol 1973; 12: 241-252.

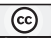

SOMERIIHTSSRESERVED published by Nature Publishing Group. This work is licensed under the Creative Commons Attribution-Noncommercial-No Derivative Works 3.0 Unported License. To view a copy of this license, visit http://creativecommons.org/licenses/by-nc-nd/3.0/

\section{Supplementary Information accompanies the paper on Cell Death and Disease website (http://www.nature.com/cddis)}

